\title{
Public-Private Partnerships for Climate Technology Transfer and Innovation: Lessons from the Climate Technology Centre and Network
}

\author{
Woo Jin Lee*D, Irma Juskenaite and Rose Mwebaza \\ Climate Technology Centre and Network (CTCN), UN City, Marmorvej 51, 2100 Copenhagen, Denmark; \\ i.juskenaite@unido.org (I.J.); mwebaza@un.org (R.M.) \\ * Correspondence: woo.lee@un.org; Tel.: +45-5261-7146
}

Citation: Lee, W.J.; Juskenaite, I.; Mwebaza, R. Public-Private Partnerships for Climate Technology Transfer and Innovation: Lessons from the Climate Technology Centre and Network. Sustainability 2021, 13, 3185. https://doi.org/10.3390/ su13063185

Received: 17 February 2021

Accepted: 11 March 2021

Published: 15 March 2021

Publisher's Note: MDPI stays neutral with regard to jurisdictional claims in published maps and institutional affiliations.

Copyright: (c) 2021 by the authors. Licensee MDPI, Basel, Switzerland. This article is an open access article distributed under the terms and conditions of the Creative Commons Attribution (CC BY) license (https:// creativecommons.org/licenses/by/ $4.0 /)$.

\begin{abstract}
The 2030 Agenda for Sustainable Development and the Sustainable Development Goals (SDGs), the Paris Agreement, and a number of important agreements call on the United Nations (UN) to strengthen a relationship with the private sector to develop and transfer climate technology in global action on climate change. The Technology Mechanism (TM) is anchored in the UN Framework Convention on Climate Change as a key enabler for the attainment of the Goals of the Paris Agreement. The growing interest for collaboration with the private sector sets new ambitions for the UN Climate Technology Centre and Network (CTCN). The active engagement of the private sector is critical for successful technology transfer and successful innovation. This paper reviews and analyses the role of the private sector in facilitating technology transfer in CTCN's Technical Assistance. Furthermore, the shared interest for partnership between the CTCN and the private sector was evaluated by analysing in-depths interviews with major CTCN stakeholders. Based upon this analysis, several recommendations are made on how to enhance public-private partnerships in order to strengthen private sector participation in climate technology transfer activities with a special focus on technology-push and market-pull innovation.
\end{abstract}

Keywords: private sector; technology transfer; innovation; public-private partnership; technologypush; market-pull

\section{Introduction}

To achieve an effective, long-term global response to climate change and to promote sustainable development, technology innovation is becoming more critical in delivering environmentally and socially sound, cost-effective, and better-performing climate technologies at a larger and more widespread scale [1]. The Climate Technology Centre and Network (CTCN) was established as part of the Technology Mechanism (TM) (the United Nations Framework Convention on Climate Change (UNFCCC) Technology Mechanism consists of two bodies: Technology Executive Committee (TEC) and the Climate Technology Centre and Network (CTCN)) in 2013 to address these issues with technology under the United Nations Framework Convention on Climate Change (UNFCCC) governance [2]. With the mission to connect developing countries to climate technology solutions, knowledge, and financing, more than 320 technology transfers are underway in more than 100 countries in various sectors.

While it is undeniable that the public sector still plays a key role in developing and supporting markets for climate technologies, there is a growing interest and commitment from the private sector to collaborate with different partners in promoting early deployment to create new markets through technology provision, financial support, and regulations to overcome particular barriers to deployment. The Hudson Institute confirms that private financial flows from all donor countries to aid-recipient countries account for $85 \%$ of their economic engagement with developing countries, whereas government (public) aid 
represents only $15 \%$ of the total engagement, the reverse of some 40 years ago [3]. Moreover, $92 \%$ of renewable energy financing is coming from the private sector [4], and recent research also shows climate technology investments far outpace, at five times, those of venture capital (VC) market rate from 2013 to 2019 [5]. New, innovative climate technologies are constantly being introduced to offset the impact of everyday activities, which causes climate change to turn into big business and the private sectors are taking notice.

This is the reason why a number of agreements including the 2030 Agenda for Sustainable Development and the Sustainable Development Goals (SDGs), and the Paris Agreement recognise and call on the UN to cultivate a strengthened relationship with the private sector. By providing its three core services of Technical Assistance, knowledge sharing, and collaboration, the CTCN matches national officials from developing countries with technology experts and financiers from its network. The analysis of the value proposition for the private sector undertaken as part of this study showed that, as of now, similar organisations in the market do not offer the exact services as the CTCN for private companies. They only offer the possibility for networking, learning, or technical assistance, but not the full package, thus putting CTCN in a niche position.

Thus, in this paper, in order to map the private network members' interest and participation in the CTCN's activities, we primarily identified various roles of the private sector as implementor, incubator, and investor in different stages of climate technology transfer especially during the CTCN Technical Assistance, based on a staged innovation model established in our previous work [6]. In addition, the shared interest for partnership between the CTCN and the private sector was evaluated as our secondary research by analysing in-depth interviews with current and potential network members, in addition to other partners successfully working with the private sector like the United States Agency for International Development (USAID). Based on the research methods of mapping and interviews, recommendations for enhanced public-private partnership (PPP) are proposed for climate technology transfer innovation by tailoring each role of the private sector in technology-push and market-pull innovation.

\section{Theoretical Backgrounds}

\subsection{Technology-Push versus Market-Pull Innovation}

Successful technology transfer involves the development of new technologies and their introduction into the marketplace through specific products as part of the overall technology development and transfer processes. Thus, technology innovation requires both ensuring the availability (i.e., supply) of new climate technologies and products based on these technologies, and creating and sustaining markets (i.e., demand) for these products. Furthermore, the front and back ends of the innovation chain are intimately interrelated in that the kind of design, research, and development carried out to develop new climate technologies and products are shaped by the markets, i.e., the perceived needs and preferences of consumers (this is referred to as 'market-pull'); on the other side, the availability of new technologies also shapes markets by changing the economics of the market or by offering new and attractive options to consumers (referred to as 'technology-push') [7].

From a public-policy perspective, the main tools available to the government for technology-push are direct research and development $(R \& D)$ funding for various $R \& D$ performers (universities, government research laboratories, and firms), in addition to tax incentives to promote R\&D. On the market-pull side, the main policy instruments are government procurement to create or support a market for a particular technology, regulations, and standards, and tax incentives/subsidies to influence consumers' purchasing decisions [8].

\subsection{Staged Innovation}

The literature is in consensus on the role of academic/research institutions, the government, and the private sector — the three elements also referred to as the 'Triple Helix'—in 
stimulating innovative activities [9]. From the technology innovation point of view, climate technology transfer can take place when the innovative findings from research conducted by academic and research institutions, or technology-based companies (technology providers) are transferred to local proponents, including the private sectors like small and medium enterprises (SMEs), consulting firms, venture capitalists, etc. within developing countries (technology users). As a matchmaker between the technology providers and users, the $\mathrm{CTCN}$ has delivered various types of Technical Assistance projects in response to the requests from the developing countries, and many different actors are involved in the different types of Technical Assistance activities based on the interaction within the innovative Triple Helix. In our previous study [6], we divided the CTCN Technical Assistance into three stages to consider innovative activities within the CTCN networks: the first stage of technology outsourcing, the second stage of technology demonstration, and the third stage of technology diffusion. By using our previous staged innovation model, in this study, we could identify each role of a targeted player, i.e., private sector among various stakeholders at each stage of some of our empirical Technical Assistance data (Table 1) and design partnerships strategically for the private sector to boost its different role in each stage of climate technology transfer and innovation. These six examples were cautiously selected by the CTCN Technical Assistance specialists among the projects completed by 27 private network members from all the previous Technical Assistance cases (214 as of December 2020).

Table 1. Technical Assistance examples implemented by network members from the private sector.

\begin{tabular}{|c|c|c|c|}
\hline Stage & Title of Technical Assistance & Country & Private Member \\
\hline \multirow{2}{*}{$\begin{array}{l}\text { First, Technology } \\
\text { outsourcing }\end{array}$} & Solomon Water and Energy Efficiency and Self-Generation Plan & Solomon Islands & PwC Price Water House India \\
\hline & $\begin{array}{l}\text { Saline water purification for households and low-cost durable } \\
\text { housing technology for coastal areas of Bangladesh }\end{array}$ & Bangladesh & Glory and Tech \\
\hline \multirow{2}{*}{$\begin{array}{l}\text { Second, Technology } \\
\text { demonstration }\end{array}$} & Support for e-mobility transition in Jakarta & Indonesia & Cadmus Group LLC \\
\hline & $\begin{array}{l}\text { Pilot demonstration of Energy Service Company (ESCO) model } \\
\text { for greenhouse gases emission reduction in the cement sector }\end{array}$ & Viet Nam & Econoler \\
\hline \multirow{2}{*}{$\begin{array}{l}\text { Third, Technology } \\
\text { diffusion }\end{array}$} & $\begin{array}{c}\text { Substantial GHG emissions reduction in the cement industry } \\
\text { by using waste heat recovery combined with mineral carbon } \\
\text { capture and utilization }\end{array}$ & South Africa & Taiheiyo Cement Corporation \\
\hline & $\begin{array}{c}\text { Incubating Climate Technologies in Small and Medium } \\
\text { Enterprises in Chile }\end{array}$ & Chile & Carbon Trust \\
\hline
\end{tabular}

\section{Results}

3.1. Role of the Private Sector in the CTCN Technical Assistance

3.1.1. Role as Implementor during the First Stage of Technology Outsourcing

As the first Technical Assistance example for the first stage of climate technology in Table 1, one of the private sector network members, PWC Ltd. undertook the assignment to provide Technical Assistance for the 'Solomon water for energy efficiency and self-generation plan' [10]. To reduce the reliance of Solomon water on fossil fuel for energy requirements, a final consolidated feasibility report on possible measures for energy efficiency (EE) and self-generation options (SGO) was prepared by employing the field data collection from pump station activities with energy monitoring systems, implemented by the private company. Through the Technical Assistance implementation, some quantitative data showed that lifetime energy saving identified was $4670 \mathrm{MWh}$ of electricity and also the estimated emission reduction over the lifetime of the suggested EE and SGO improvements was 3260 tCO2-e and 4710 tCO2-e, respectively. The percentile of energy-saving and GHG emission reduction after the Technical Assistance implementation is shown in Figure 1. 


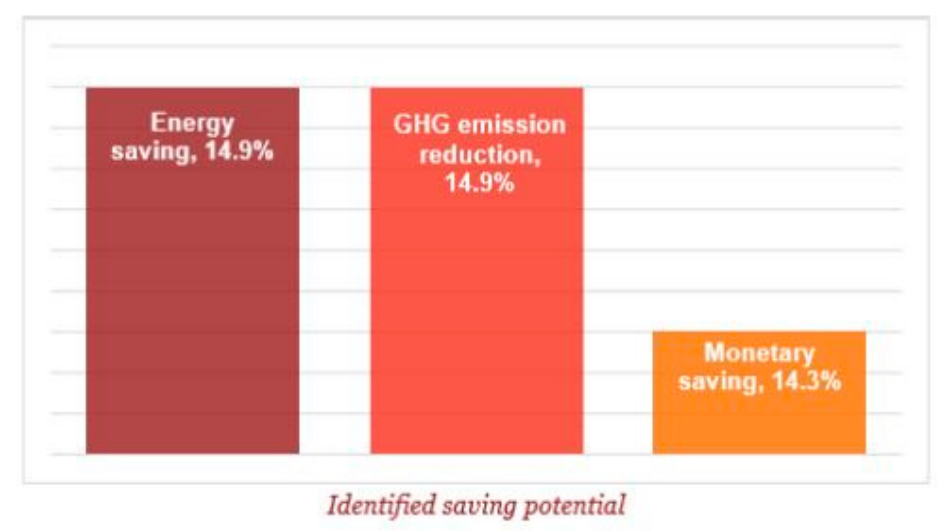

Figure 1. Energy-saving, greenhouse gas (GHG) emission reduction, and monetary saving of Solomon water pumps.

Bangladesh, one of the most vulnerable countries to climate change, submitted a request to $\mathrm{CTCN}$ for Technical Assistance in designing and delivering 'saline water purification for households and low-cost durable housing technology for coastal areas' [11]. This project was conducted by a consortium of government-funded research institutions of Green Technology Centre-Korea, Korea Institute of Civil Engineering and Building Technology, and the private company of Glory and Tech. Throughout this cooperation, new fabrication methods such as aerated bricks using fly ash, a mixture block of rice straw (cellulose) with soil, and vacuum extrusion panel etc. were outsourced from the pubic private consortium as innovative technologies for housings of the southern coastal area of Bangladesh.

According to the findings from the above Technical Assistance examples based on the staged innovation model [6], during the first stage of technology transfer, most of the requests from technology users in developing countries (country-driven) were found to involve open networking with the private sectors as external technology providers, in order to facilitate new technology from outside into the process. Therefore, this role of the private sector network member in outsourcing technology during the CTCN Technical Assistance activities can be identified as a 'technology implementor' [12].

\subsubsection{Role as Incubator during the Second Stage of Technology Demonstration}

The Technical Assistance example of 'support for e-mobility transition in Jakarta' is developing an investment plan for introducing e-mobility in public and government vehicles [13]. The private consulting firm Cadmus Group will deliver upscaling solutions of e-mobility such as emission reduction, urban resiliency improvement, and new green business opportunities on the basis of local contexts, policy requirements, and practical actions for full scale-up through close collaboration with the Indonesian government. Through this Technical Assistance implementation, it is estimated that fully renewable energy-powered electric buses can reduce $2680 \mathrm{CO} 2$-e grams per mile over diesel-based buses and $2364 \mathrm{CO} 2$-e grams per miles over gas-based buses.

Moreover, another CTCN private network member, a consulting firm Econoler, plays a role as an incubator to provide quality energy efficiency, GHG emissions reduction, and renewable energy professional services while respecting sustainable development principles in Vietnam. The Technical Assistance (pilot demonstration of energy savings company model for GHG mission reduction in the cement sector in Vietnam) is currently under implementation to develop an energy savings business model for the highly energyintensive Vietnam cement production companies [14].

From the Technical Assistance examples of the second stage for technology demonstration, we observed that the private network companies like consultant firms, technologybased SMEs, start-ups, venture capitalists, angel investors, etc. are willing to play a role as 'technology incubators' for scaling up, demonstration, and strategical development of 
business model from the pre-existing technologies [15]. In general, this can be done by various collaborations such as strategic alliances among the public (governments, research institutions), private (business), and academic (university professionals) partnerships, depending on their respective roles and shared interests.

\subsubsection{Role as Investor during the Third Stage of Technology Diffusion}

In order to achieve the national goal of 'reducing emissions by 34\% from the 1990 level by 2020 ', the Association of Cementitious Material Producers (ACMP), the industry body for the cement sector in South Africa, has been working to scale up innovative low carbon technologies for further reducing GHG emissions. Hence, the government in South Africa requested the CTCN for assistance in conducting a feasibility study for 'substantial GHG emissions reduction in the cement industry by using waste heat recovery combined with mineral carbon capture and utilization' [16]. The association of the private sector, Taiheiyo Cement Corporation, played a role in scaling up the existing low carbon technologies such as waste heat recovery (WHR) and mineral carbon capture and utilization (MCC\&U) technology to a commercial level. Hybrid low carbon technology using well-established WHR technology powered by recovering energy from $\mathrm{CO}_{2}$-rich exhaust gases has been widely deployed with $30 \%$ energy reduction in the cement industry of South Africa, as described in Figure 2.

Furthermore, the Technical Assistance includes assessing the cost efficiency of the technologies and marketability of recycled by-products from concrete wastes and designing a business plan for the project implementation in South Africa. In order to convince financiers or any risk-takers to scale up the project to the commercial level, innovative technologies such as WHR and MCC\&U need a demonstration step. Thus, this Technical Assistance covered exploring different options for financing the bench-scale and pilot-scale plants, e.g., South Africa Government Investment Incentives from R\&D to commercial-scale plants, financial assistance, and subsidies for the construction of a mobile bench-scale plant, or a mixture of traditional loan-equity finance together with various incentives provided by the government and international organisations.

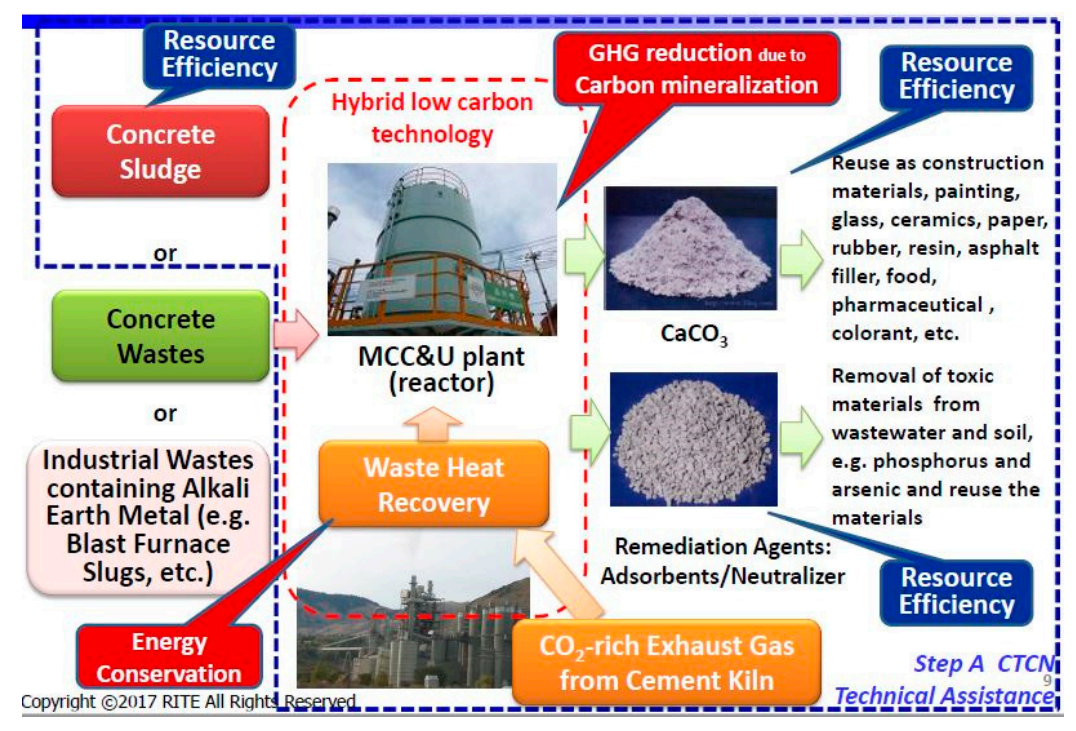

Figure 2. GHG reduction using hybrid low carbon technology comprising waste heat recovery and mineral carbon capture and utilization technology.

In Chile, the Technical Assistance for 'incubating Climate Technologies in Small and Medium Enterprises in Chile' was implemented by a private company Carbon Trust [17]. Private sector organisations including 31 local SMEs in the agri-food sector were engaged throughout the assistance in order to understand the local context better, validate findings, and share project results. This project was also supported by various financial assistance 
schemes provided by the Green Investment Bank, a facility to invest in green tech in the country, and international organisations, such as the Green Climate Fund (GCF). GCF is the financing arm of the UNFCCC fostering climate finance investment, including private investment.

During the third stage of technology diffusion, it is common that private companies try to play a role as 'investors' through collaboration with other public or private funding entities, which is known as 'blended finance' [18]. The output of CTCN's Technical Assistance support can be easily transformative by allocating external private funding resources based on the learning from the feedback of customers and the broader society, e.g., economic sectors, municipalities, and national governments, led by market-pull innovation [19].

\subsection{Shared Interest between the CTCN and the Private Sector}

A key component of the CTCN is its network, consisting of a variety of climate technology experts and institutions that can engage in the CTCN's activities to deliver climate solutions at the requests of developing countries, using their technical knowledge and expertise. As of January 2021, 624 organisations from more than 90 countries participate in the CTCN network. Figure 3 shows the distribution of the current CTCN's network members by type of institution.

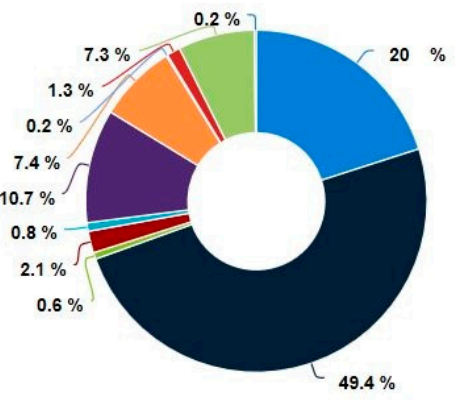

Research and academic institution

Intergovernmental orgate sector organization

Partnership Public sector organisation Regional organisation

Figure 3. Distribution of network members by type of institution, January 2021(UN Climate Technology Centre and Network (CTCN) information).

Here, we can observe that almost half of the CTCN network members (49.5\%) are from the private sector, mainly SMEs, followed by research and academic institutions (20.7\%), and other organisations. It is noticeable that there is a growing interest for the private companies to join as key CTCN network members; however, their participation in the CTCN projects is currently low. According to our internal analysis [20], only 27 members among 304 private network members, participated in Technical Assistance projects, mostly focusing on the latter stages of the technology transfer cycle, such as piloting and deployment of technologies in local conditions or market creation. This signifies the necessity of a market-oriented strategy innovation considering the different roles and interests of the private sector.

In order to investigate private sector interest to collaborate with the CTCN and how we can facilitate the partnership further, we conducted in-depth interviews, with major stakeholders including current and potential network members from the private sector, in addition to some government representatives. Key questions for the interviewees were (1) main reasons to join the CTCN in terms of roles of interests of the private sector, (2) key success factors (impacts or main lessons) in collaborating with the CTCN, (3) main enablers and barriers for engaging the network, and (4) recommendations/advice for the CTCN. The interviewees and their answers are summarised as keywords in Table 2. According to the interviews, the network members joined the CTCN with the following reasons: (1) possibility to apply for the CTCN Technical Assistance projects (75\% of the respondents), (2) collaborative opportunities with other network members $(61 \%)$, (3) learning from 
and exchanging knowledge with other members (48\%), (4) building relationships with the government focal points (43\%), and (5) seeking business opportunities to enter new markets $(41 \%)$.

Table 2. In-depth interview with the CTCN stakeholders.

\begin{tabular}{|c|c|c|}
\hline \multicolumn{2}{|c|}{ CTCN Stakeholders } & Answers in Keywords \\
\hline \multirow{4}{*}{$\begin{array}{l}\text { Current CTCN } \\
\text { Network member }\end{array}$} & $\begin{array}{l}\text { Kenyan Climate Innovation } \\
\text { Centre, Kenya }\end{array}$ & $\begin{array}{l}\text { Technology transfer (technical assistance and financial assistance); lack of knowledge; lack of } \\
\text { financing; continuity and long-term engagement; innovation; qualitative and quantitative } \\
\text { success factors; lack of internal structure and corporate governance among SMEs; some } \\
\text { hesitation to share detailed information from private sector }\end{array}$ \\
\hline & Econoler, Canada & $\begin{array}{l}\text { Promote know-how in climate-smart technologies; CTCN network; consultancy assignments; } \\
\text { return on investment; time, money and effort. Access to tenders; community of practice; } \\
\text { expanding climate change portfolio to other geographies; business development opportunity } \\
\text { not clear }\end{array}$ \\
\hline & Ramboll, Denmark & $\begin{array}{l}\text { Access to tenders; community of practice; expanding climate change portfolio to other } \\
\text { geographies; business development opportunity not clear; difficult to devote pro-bono time; } \\
\text { webinars; trainings; no risks; collaboration; reputation }\end{array}$ \\
\hline & Solvatten, Sweden & $\begin{array}{l}\text { Network for knowledge and contacts; opportunities for procurement and tenders; need for } \\
\text { internal capacity; innovation; result based impact }\end{array}$ \\
\hline \multirow{4}{*}{$\begin{array}{l}\text { Potential } \\
\text { Network member }\end{array}$} & Adarsh Polymer, Kenya & $\begin{array}{l}\text { Learn technologies; sharing knowledge; help others; achieve more; network; engagement; } \\
\text { common objectives }\end{array}$ \\
\hline & European Energy, Denmark & $\begin{array}{l}\text { Prioritised access to a specific country/market; network and/or understanding of the } \\
\text { market/country; engagement; facilitation; network; funding of projects unclear; limited risk }\end{array}$ \\
\hline & Exotic EPZ, Kenya & $\begin{array}{l}\text { Identification of the right technologies; innovation; private sector is very result oriented; } \\
\text { network; engagement; mentorship and training; create value; create impact; time invested }\end{array}$ \\
\hline & $\begin{array}{l}\text { NIBE Energy Systems, } \\
\text { Sweden }\end{array}$ & $\begin{array}{l}\text { Possibilities for new markets; matchmaker; network; new contacts; information about } \\
\text { political environment; local presence in the country; how much information to share }\end{array}$ \\
\hline \multirow{2}{*}{$\begin{array}{l}\text { Government } \\
\text { representative }\end{array}$} & $\begin{array}{l}\text { United States Agency for } \\
\text { International Development } \\
\text { (USAID) }\end{array}$ & $\begin{array}{l}\text { Co-creation mutually beneficial achievements to collaboration; private sector might have } \\
\text { some solutions that they want to propose; private sector as potential co-founders of } \\
\text { solutions; forms of acquisition and assistance; monitoring, evaluation and learning; } \\
\text { alignment between the private sector's interest and the agency's initiatives; principles of } \\
\text { co-creation are networking, engagement and developing shared solutions }\end{array}$ \\
\hline & $\begin{array}{l}\text { Ministry of Science and ICT, } \\
\text { Republic of Korea }\end{array}$ & $\begin{array}{l}\text { Increase their income; establish and enhance a network for business development and } \\
\text { technology diffusion with the government of South Korea and developing countries; } \\
\text { innovation; different partners around the world; CTCN as a trusted partner that ensures } \\
\text { developing a higher quality pipeline and provides access to different partners; potential for } \\
\text { scale up }\end{array}$ \\
\hline
\end{tabular}

Moreover, the interviews enabled us to identify the mutual interests of the CTCN and the private sector, as presented in Table 3 . The findings from the interviews indicate that there is a need to combine the role of the private sector as implementor within the CTCN network and the development of new markets as incubator or investor to fulfil the common goals of the two parties that form the partnership for low-carbon and resilient technology innovation [21].

Table 3. Shared interest for CTCN and the private sector.

\begin{tabular}{ccc}
\hline CTCN Interest & Shared Interest & Private Sector Interest \\
\hline $\begin{array}{c}\text { Connect countries to climate } \\
\text { technology solutions }\end{array}$ & Developing existing and new markets & $\begin{array}{c}\text { Interest and ability to find and } \\
\text { develop new markets }\end{array}$ \\
\hline $\begin{array}{c}\text { Enhance the network, technical expertise, } \\
\text { operational and project delivery capacity, } \\
\text { scale (multi-country) }\end{array}$ & Combining resources/partnering & $\begin{array}{c}\text { Access to network: skills, knowledge, } \\
\text { technical expertise, financial resources }\end{array}$ \\
\hline $\begin{array}{c}\text { Strengthen cooperation with governments } \\
\text { and donors, the private sector }\end{array}$ & $\begin{array}{c}\text { Public-private policy dialogue focused on } \\
\text { addressing climate change }\end{array}$ & $\begin{array}{c}\text { Reduction of regulatory, political } \\
\text { risks, understanding of business and } \\
\text { other regulations }\end{array}$ \\
\hline Encourage innovations & Innovation & $\begin{array}{c}\text { Drive to innovate, compete and } \\
\text { constantly increase efficiency }\end{array}$ \\
\hline
\end{tabular}




\section{Discussion}

As reported in our previous research [6], it is noted that each percentage of the CTCN Technical Assistance regarding the three service stages is about $80 \%, 15 \%$, and $5 \%$, respectively, which means that the CTCN has mainly focused on climate technology outsourcing at the first stage of technology transfer, rather than on technology demonstration at the second stage, or on technology diffusion at the third stage. Moreover, most of the previous CTCN Technical Assistance services implemented by the private network members were mostly involved in the latter two stages of technology transfer. This indicates that there is a need for two types of PPP strategies, i.e., (1) a short-term strategy to increase the engagement of the current network members (private sector as implementor during the first stage) and (2) a long-term strategy for shifting from technology-push to market-pull innovation to attract the new members and engage the current ones as incubator or investor during the second and third stages), as described in Figure 4.

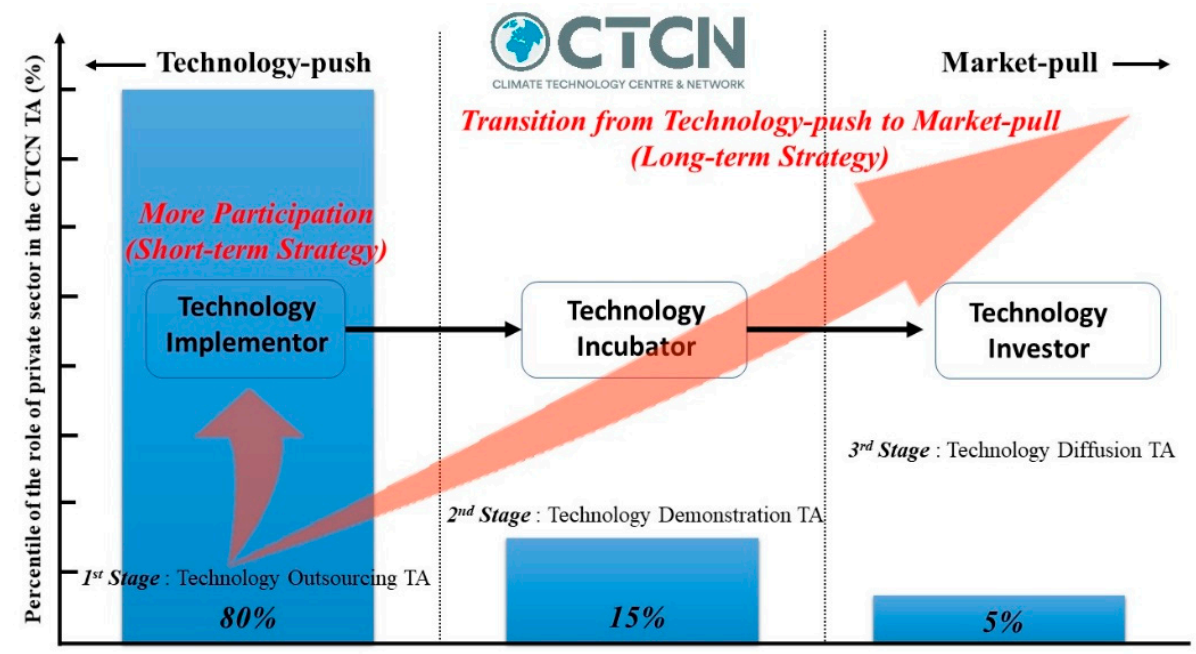

Figure 4. Innovative roles of the private sector during three stages of the CTCN Technical Assistance.

\subsection{The Short-Term Strategy: More Engaged Network Members in the First Staged Technical Assistance}

Since the portion of the first staged Technical Assistance is still significant, it seems obvious that the CTCN can consider temporarily setting up a strategy for enhancing the participation of the private sector in this stage as a technology implementor. This directly satisfies the shared interest of resource combination (Table 2) by technology outsourcing from the private sector (as implementor) within the CTCN network, denoting 'technologypush strategy innovation'. For this purpose, two action plans are on-going by the CTCNone is running special innovative activities for 'dormant' private network members to support local small and medium-sized enterprises (SMEs), and the other is the digitalization of the CTCN Technical Assistance.

Aligned with an innovative trend in other organisations to help developing countries by establishing climate innovation centres or by running various entrepreneurial programmes for different stakeholders, the CTCN has started to run a special private sector innovation programme which focuses on the identification of challenges and specific solutions for the SMEs, through the SME Technology Clinics [22]. This activity aims to support the transformation of the national industrial SME markets by helping industrial SMEs to take up climate technologies by (1) introducing innovative climate technologies and international climate technology providers, (2) creating linkages to finance, and (3) building the capacity and awareness of the local industrial SMEs. Therefore, this has been a good opportunity for the inactive private network members to join in technology outsourcing as innovative technology implementors for the local SMEs. 
In addition, in 2020, the CTCN also launched the Youth Climate Innovation Labs [23], aiming to support countries in incentivizing innovation by improving their national systems of innovation. Two virtual Youth Climate Innovation Labs (one in Africa and one in Asia-Pacific) took place in November 2020 and December 2020, and they attracted more than 800 participants from more than 50 countries. It focused on developing solutions to CTCN partner SMEs identified needs and challenges through youth engagement and design thinking processes. By participating in these innovative activities as climate technology implementors, private network members can transfer their cutting-edge technologies and skills to the local SMEs within target countries.

Furthermore, for more innovative engagement of the private sector network members in technology outsourcing for Technical Assistance, it is worthwhile to note that climate technology solutions can be converged digital technologies, i.e., machine learning, cloud computing, Internet of Things (IoT), and blockchain technology. These emerging technologies can enhance information transparency, increase automation, and enable direct interactions between the private sector network members by creating a trusted information layer by combining IoT sensors (data collection), machine learning (verification and analysis), and blockchain technology (distribution and execution). Previously, innovative early warning systems for enhancing climate resilience were developed in Thailand [24] by connecting various private digital technologies with software (SW) modelling and associated climate data. Moreover, these IT-incorporated Technical Assistance results implemented by the private sector during the first stage, can be transformed during the later second and third stages into valuable outputs for involving other private-sector network members, who are seeking new collaboration opportunities with the CTCN.

\subsection{Long-Term Strategy: Shifting to Market-Pull Innovation}

For a sustainable strategy to integrate more members from the private sector into CTCN Technical Assistance, it is important to recognise that the private sector always tends to consider business or market creation for profit sharing [25]. This leads to their dominant roles as 'incubators for technology demonstration' at the second stage, or 'investors for market creation' at the third stage of technology diffusion, rather than as 'implementors for technology provision' at the first stage. Therefore, we can state that technology innovation should transform steadily from technology-push (first stage) to market-pull (second and third stages) by raising the Technical Assistance requests for private incubators or investors from the developing countries, as indicated in Figure 4.

The increase of requests for market-pull innovation is feasible, if it is recognised that the CTCN follows a 'two-sided network model', as described by Stabel and Fjeldstad [26]. This is known as a platform for exchange between two distinct user groups that provide each other with the benefits of a large network. Figure 5 shows the CTCN's two-sided network model.

Side1

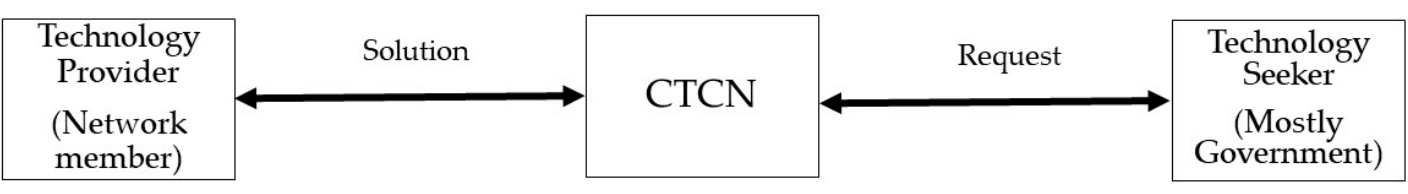

Figure 5. The two-sided network created by CTCN.

In the case of the CTCN, there are technology providers/knowledge owners (network members, UN organisations, other partners) on one side, and technology/knowledge seekers (mainly governments interested in climate change, climate technology, etc.) on the other side. Accordingly, under this circumstance, external values like technology requests and solutions are smoothly transferred between the service provider and customer, i.e., technology providers from the private sector can easily access all requests from technology seekers (government) by joining the CTCN network. This is known as a country-driven re- 
questing process for the Technical Assistance from the $\mathrm{CTCN}$, implying customer-oriented open innovation [6]. Therefore, we can state that this two-sided network system is very operational to effectively customise the requests and solutions that are market-friendly by creating new linkages and reinforcing or de-linking existing connections.

Within the two-sided networks, CTCN can, therefore, use 'co-creation' as a strategy to facilitate sustainable engagement of the private sector, especially as an incubator or an investor. Recognizing that co-creation activities are the processes of networking or collaboration with different stakeholders to achieve the common goals from the shared interests, the CTCN can employ the co-creation strategy as a sustainable method in establishing a robust partnership with the private sector. It can also foster innovation and this time-bounded process will drive mutually beneficial achievements to collaboration, according to our interview with the USAID.

As a good example of co-creation for sustainable engagement of the private sector, the CTCN can upgrade the previous SMEs programme to a five-year co-creation programme with three phases. Figure 6 shows the proposed co-creation process of the upgraded SMEs programme. In Figure 6, first, both the private sector as implementors and SME partners from developing countries are invited to co-creation workshops, facilitated by the two-sided network system of the CTCN. During the workshops, various private network members 'incubate' a scope of work together to find the most needed Technical Assistance requests and solutions for SMEs, on the basis of the shared interests (capacity building, pilot product, business model, regulations, market entry, etc.). The last step is co-investment for new market creation, where the private sector acts as an investor. Through this co-creation process, private partners, especially as incubators or investors, could develop Technical Assistance projects successfully aligned with joint objectives, and the SMEs could learn a lot on the way as well as expand their networks.

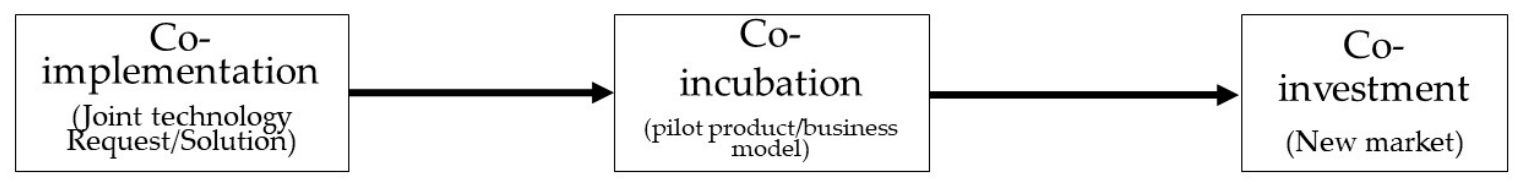

Figure 6. The proposed co-creation process of the SMEs programme.

Second, communication is a key tool for engaging the private members in the CTCN technology diffusion activities during the third staged Technical Assistance [27]. The CTCN has been facilitating regular dialogues among different stakeholders and the sharing of good practices and climate-smart technologies through the existing on-line knowledge information sharing platform (www.ctc-n.org, accessed on 1 January 2021). The CTCN platform has thousands of different information resources from a broad array of international sources (publications, case studies, tools, national climate plans and policies, climate technology and product descriptions, webinars, etc.). Moreover, enhanced IT connectivity to the CTCN platform is obviously a motivational driver to keep the current members engaged and encourage new ones to seek collaborative works with the CTCN for boosting market-pull innovation. Further research on the digitalization of the CTCN as a demonstration of using the technology framework under the UNFCCC will be elaborated in a future publication.

To summarise, the suggested short-term and long-term PPP strategies and their related activities could strengthen the partnerships and enhance climate technology transfer innovation, depending on various roles of the private sector during the three stages of the CTCN Technical Assistances, as indicated in Figure 7. 


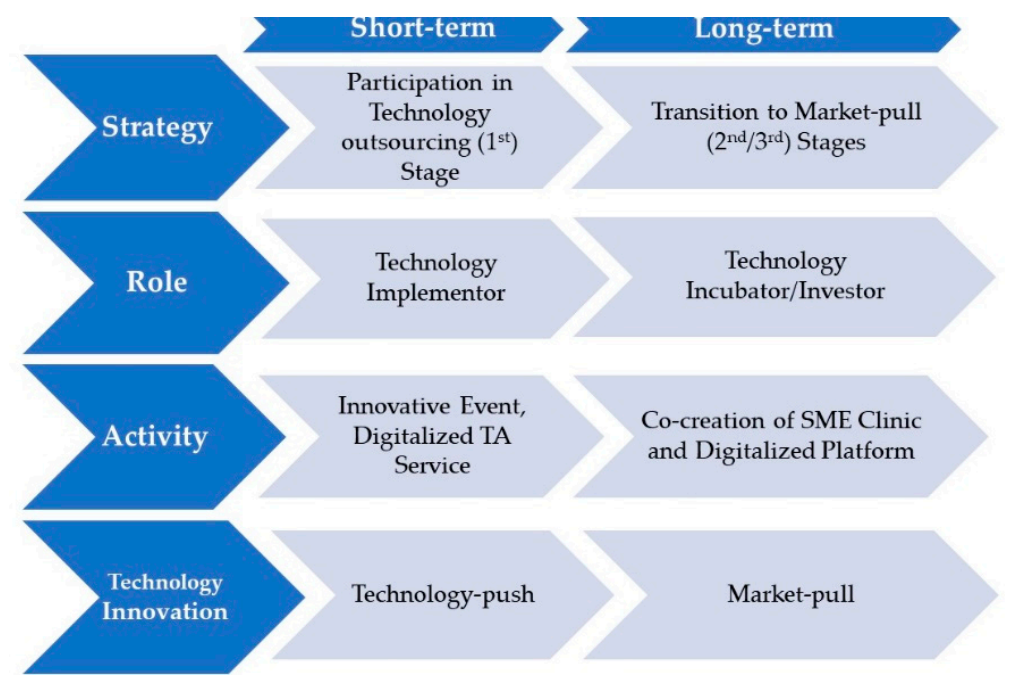

Figure 7. Schematic of new public-private partnership (PPP) strategy for climate technology transfer innovation.

\section{Conclusions}

In this paper, the various roles of the private sector during climate technology development and transfer processes were successfully identified by analysing the previous Technical Assistances implemented by the private network members on the basis of staged innovation. Each role as technology implementor, incubator for technology scale-up and demonstration, and investor to diffuse the technology into the market was clearly revealed in each stage of technology outsourcing, technology demonstration, and technology diffusion during various CTCN Technical Assistance activities, respectively. Furthermore, we evaluated the shared interest for the partnership between the CTCN and the private sector through in-depth interviews with major stakeholders including current and potential network members from the private sector, in addition to some government representatives. This implies a need to combine the role of the private sector as implementors within the CTCN network and the development of new markets as incubators or investors to fulfil the common goals of the $\mathrm{CTCN}$ and the private sectors. Based on this analysis, we proposed two types of PPPs. Firstly, short-term PPPs and related activities were introduced to enhance the participation of the private sector as implementors in the technology outsourcing CTCN Technical Assistance activities. Then, long-term and corresponding activities for a sustainable private partnership were suggested to shift the private sector's role to incubator or investor for market-pull innovation.

Author Contributions: Conceptualisation, W.J.L.; methodology, I.J.; writing-original draft preparation, W.J.L. and I.J.; writing-review and editing, supervision, R.M. All authors have read and agreed to the published version of the manuscript.

Funding: This research received no external funding.

Informed Consent Statement: Not applicable.

Data Availability Statement: Not applicable.

Acknowledgments: This study was supported by a secondment programme in the Ministry of Science and ICT (MSIT), Republic of Korea. Special thanks to S.E. Bae and Jae for their ingenious advice.

Conflicts of Interest: The authors declare no conflict of interest. 


\section{References}

1. Decision 15/CMA.1, Annex. Available online: https://unfccc.int/ttclear/misc_/StaticFiles/gnwoerk_static/tn_meetings/61a8 aadf7134442295729d3090ceb67f/502e06bce7b046a8974234413b1ad5a9.pdf (accessed on 10 December 2020).

2. UNFCCC Subsidiary Body for Scientific and Technological Advice Thirty-Eighth Session Bonn, 3-14 June 2013 Agenda Item 6: Development and Transfer of Technologies and Implementation of the Technology Mechanism. Available online: https://unfccc. int/resource/docs/2013/sbsta/eng/111.pdf (accessed on 15 December 2020).

3. Hudson Institute Releases Report Measuring Global Philanthropy and Remittances, 2 March 2017 Press Release. Available online: https:/ / www.hudson.org/research/13404-hudson-institute-releases-report-measuring-global-philanthropy-andremittances (accessed on 20 December 2020).

4. Renewable Energy Finance Brief 02 January 2020: Renewable Energy Investment Trends. Available online: https://www.irena org/media/Files/IRENA/Agency/Publication/2020/Jan/IRENA_RE_finanace_Institutional_capital_2020.pdf (accessed on 21 December 2020).

5. The State of Climate Tech 2020. Available online: https://www.pwc.com/gx/en/services/sustainability/assets/pwc-the-stateof-climate-tech-2020.pdf (accessed on 15 December 2020).

6. Lee, W.J.; Mwebaza, R. The Role of the Climate Technology Centre and Network as a Climate Technology and Innovation Matchmaker for Developing Countries. Sustainability 2020, 12, 7956. [CrossRef]

7. Lubik, S.; Lim, S.; Platts, K.; Minshall, T. Market-pull and technology-push in manufacturing start-ups in emerging industries. J. Manuf. Technol. Manag. 2013, 24, 10. [CrossRef]

8. Large, D.W.; Barclay, D.W. Technology transfer to the private sector: A field study of manufacturer buying behavior. J. Prod. Innov. Manag. 1992, 9, 26. [CrossRef]

9. Abdurazzakov, O. Role of technology transfer mechanisms in stimulating innovation. Oeconomia 2015, 14, 5-12.

10. CTCN Technical Assistance: Solomon Water for Energy Efficiency and Self-Generation Plan. Available online: https://www.ctcn.org/system/files/dossier/3b/Final\%20report_Draft_20200327.pdf (accessed on 1 January 2021).

11. CTCN Technical Assistance: Saline Water Purification for Households and Low-Cost Durable Housing Technology for Coastal Areas. Available online: https:/ / www.ctc-n.org/system/files/dossier/3b/D3.3\%20Technology \%20solutions $\% 20$ for $\% 20$ saline $\%$ 20water\%20purification\%20at\%20household\%20level\%20applicable\%20for\%20coastal\%20Bangladesh.pdf (accessed on 2 January 2021).

12. Biagini, B.; Miller, A. Engaging the Private Sector in Adaptation to Climate Change in Developing Countries: Importance, Status, and Challenges. Clim. Dev. 2013, 5, 242-252. [CrossRef]

13. CTCN Technical Assistance: Support for e-Mobility Transition in Jakarta. Available online: https://www.ctc-n.org/system/files/ response_plans/ctcn_ta_e-mobility_countersigned_final.pdf (accessed on 2 January 2021).

14. CTCN Technical Assistance: Pilot Demonstration of ESCO Model for GHG Mission Reduction in the Cement Sector in Viet Nam. Available online: https:/ / www.ctc-n.org/sites/www.ctc-n.org/files/request/vietnam._pilot_demonstration_of_esco_model_ for_ghg_mission_reduction_in_the_cement_sector_in_viet_nam._august_2016_0.pdf (accessed on 5 January 2021).

15. Malek, K.; Maine, E.; McCarthy, I.P. A Typology of Clean Technology Commercialization Accelerators. J. Eng. Technol. Manag. 2014, 32, 26-39. [CrossRef]

16. CTCN Technical Assistance: Substantial GHG Emissions Reduction in the Cement Industry by Using Waste Heat Recovery Combined with Mineral Carbon Capture and Utilization. Available online: https://www.ctc-n.org/system/files/dossier/3b/20 180207_ctcn_activity_report_final_rev.pdf (accessed on 10 January 2021).

17. CTCN Technical Assistance: Incubating Climate Technologies in Small and Medium Enterprises in Chile. Available online: https: / / www.ctc-n.org/system/files/response_plans/ctcn_response_plan_chile_2016000033_eng.pdf (accessed on 2 February 2021).

18. Decision 8/CP.21, Paragraph 10. Available online: https://unfccc.int/resource/docs /2015/cop21/eng /10a02.pdf\#page=13 (accessed on 6 June 2020).

19. Alkhani, R. Understanding Private-Sector Engagement in Sustainable Urban Development and Delivering the Climate Agenda in Northwestern Europe-A Case Study of London and Copenhagen. Sustainability 2020, 12, 8431. [CrossRef]

20. Juskenaite, I. Strengthening Collaboration with Small and Medium Enterprises by the United Nations Climate Technology Centre and Network. Master's Thesis, Copenhagen Business School, Frederiksberg, Denmark, 2020.

21. Weijo, R.O. Strategies for promoting technology transfer to the private sector. J. Technol. Transf. 1987, 11, 43-65. [CrossRef]

22. CTCN Website Information: Private Sector Hub. Available online: https:/ / www.ctc-n.org/network/private-sector-hub (accessed on 2 February 2021).

23. CTCN Website Information: UN on the Search for Young Tech Innovators Creating Climate Solutions. Available online: https:/ / www.ctc-n.org/news/un-search-young-tech-innovators-creating-climate-solutions-deadline-extended (accessed on 2 February 2021).

24. CTCN Technical Assistance: High Resolution Regional Climate Model Projections for Thailand. Available online: https://www. ctc-n.org/system/files/response_plans/responseplan_thailand_2015000084_signed_by_all_0.pdf (accessed on 25 February 2021).

25. Vutsova, A. The role of public-private partnership for effective technology transfer. Appl. Technol. Innov. 2014, 10, 83. [CrossRef] 
26. Stabell, C.B.; Fjeldstad, Ø.D. Configuring value for competitive advantage: On chains, shops, and networks. Strateg. Manag. J. 2008, 19, 413-437. [CrossRef]

27. Hamilton, C.; Philbin, S.P. Knowledge based view of university tech transfer-A systematic literature review and meta-analysis. Adm. Sci. 2020, 10, 62. [CrossRef] 